\section{The effects of varying levels of deprivation on the stability of dominance-submission hierarchies}

\author{
R. S. RUSKIN and C. D. CORMAN \\ West Virginia University, Morgantown, W. Va. 26506
}

Dominance hierarchies were found to be highly stable, both when members of a competing pair were under equal levels of deprivation and when the more "submissive" member of a pair competed under higher levels of deprivation than did its dominant counterpart. Significant relationships between dominance measures relating to "social encounter" and "limited access" competition were also found over the deprivation levels tested.

Research dealing with the determination of "dominancesubmission" hierarchies can be divided into two general categories: those which analyze behavioral components of social encounters between two Ss (i.e., submissive crouches, dominant postures, etc.) (Grant \& Chance, 1958; Baenninger, 1966) and those which place Ss on a deprivation schedule and determine relative dominance or submissiveness through paired comparison testing in a "limited access" situation (Candland \& Bloomquist, 1965; Uyeno, 1960). Little has been done to determine the degree of relationship between measures in these two areas, however.

The following experiments have utilized an experimental procedure in which video-taping and free-operant testing are employed to allow the emission and analysis of both types of behavior in a single experimental setting (Corman \& Ruskin, 1969).

The purpose of this research was, first, to determine the degree of relationship between these two areas of dominant-submissive behavior when the levels of deprivation are equal for all competing Ss; and second, to determine the stability of dominant-submissive relationships when competing Ss are under different levels of deprivation.

\section{EXPERIMENT 1 \\ Subjects}

Thirty-six male hooded rats, 60 to 65 days old at the beginning of testing were utilized. All Ss were housed from weaning until the end of testing in group cages with other members of the same sex. No Ss were housed in living cages with any Ss with which they were to be paired during testing. This eliminated the establishment of dominant-submissive relationships prior to testing.

\section{Apparatus}

Testing was carried out in an $18 \times 18$ in. nose-poke apparatus and monitored by Sony video-taping equipment. The nose-poke compartment has plywood walls and a grid floor, with a 11/4-in. hole positioned $1 / 2 \mathrm{in}$. above the floor on one wall. Food pellets were delivered through standard delivery mechanisms. Food reinforcement consisted of standard 45-mg Noyes pellets. A nose-poke response consisted of a complete penetration of the nose-poke opening by a competing $\mathbf{S}$.

Procedure

On the first day of testing, Ss were divided randomly into six groups. The order of presentation of Phases 1, 2, and 3 was different for each group. Round-robin paired comparison testing was administered to all group members. Selection of competitors was random. Testing of all Ss was carried out within a 2-h period each day to control for possible activity differentials relating to circadian rhythms. Temperature and light-dark cycling was held constant throughout testing.

Phase 1. Ss in all groups were placed on a 24-h food-deprivation schedule, which was maintained throughout this phase of testing. Dominance testing under competition for food reinforcement occurred in the nose-poke apparatus, and each session was video-taped for later scoring. Each daily test session lasted $15 \mathrm{~min}$. Pairings were made within each group, with no animal receiving more than one test trial per day. When each $S$ had been individually tested with all other members of his group five times, Phase 2 was initiated.

Phase 2. All Ss were given access to continuous food and water for 7 days. On Day 8 of this phase, Ss were placed on 48-h food-deprivation schedules. Testing was carried out in exactly the same manner as in Phase 1 , except that the order of pairing was altered to control for order effects in testing. Each animal was again paired five times with each other member of its group.

Phase 3. Ss were then maintained ad lib for 7 days. On Day 8, Ss were placed on 72-h deprivation schedules and round-robin, paired-test procedures, identical to those of Phases 1 and 2 , were initiated. The order of within-group pairings was again randomized to help control for progressive effects of testing.

Results and Discussion

Two measures were analyzed in the test session: the number of resolved encounters and the number of responses in the nose-poke for reinforcement. These measures represented "social encounters" and " "limited access" behaviors, respectively. The behavioral criteria which constituted a "resolved encounter" were identical to those described in Grant \& Chance (1958). Animals were scored as either a "winner" or "loser" for each pairing, and dominance hierarchies were established for each group.

Coefficients of concordance (Kendall, 1955) were computed for each measure and grouped over the five-test trials for each level of deprivation. Coefficients ranged from .691 to $.805(\mathrm{df}=5$ ) for the social encounter hierarchies $(p<.01)$ and from .702 to .821 (df $=5 ; p<.01)$ in the limited access condition. Stability of the dominance hierarchy does not appear to be significantly affected as a function of level of deprivation, at least in the 24- to $72 \cdot \mathrm{h}$ range. This would agree with results found by Candland, Matthews, \& Taylor (1968) with the domestic chicken and those of Schumsky \& Jones (1966), who utilized a runway-encounter type of competitive situation with rats.

Intercorrelations between hierarchies obtained under both social encounter and limited access conditions are presented in Table 1.

The intercorrelations between social encounter and limited access are significant to the .05 level for all groups and levels of deprivation.

At a descriptive level, correlations for all six groups were averaged for each level of deprivation and found to be $.901, .893$, and .899 for the $24-$, 48-, and 72-h levels of deprivation, respectively. These data strongly

Table 1

Spearman Rank Order Correlntions Between Social Encounter and Limited A ceess Conditions Under Three Levels of Deprivation

\begin{tabular}{|c|c|c|c|}
\hline \multirow[b]{2}{*}{ Group } & \multicolumn{3}{|c|}{ Hours of Deprivation } \\
\hline & 24 & 48 & 72 \\
\hline 1 & .924 & .876 & .883 \\
\hline 2 & .896 & .901 & .912 \\
\hline $\mathbf{3}$ & .921 & .894 & .905 \\
\hline 4 & .906 & .900 & .879 \\
\hline $\mathbf{5}$ & .875 & .911 & .896 \\
\hline 6 & .888 & .876 & .921 \\
\hline
\end{tabular}

Note-N $=6, \rho=.826, p<.05$ 
Table 2a

Experimental Group: Spearman Rank Order Correlation Coefficients Between Limited Acces Dominance Hierarchies in the 24-H Deprivation Condition in Experiment 1 , and Condition 1 and Condition 2 in Experiment 2

\begin{tabular}{ccc} 
& Condition 1 & Condition 2 \\
\cline { 2 - 3 } & $\begin{array}{c}\text { Dominant } S \text { in } \\
\text { pair deprived } 24 \mathrm{~h} . \\
\text { Submissive } S \text { in } \\
\text { proup }\end{array}$ & $\begin{array}{c}\text { Dominant S in } \\
\text { pair deprived 24 h. } \\
\text { Submissive } S \text { in } \\
\text { pair deprived } 72 \mathrm{~h} .\end{array}$ \\
\hline 1 & .836 & .852 \\
2 & .871 & .837 \\
3 & .778 & .604 \\
4 & .903 & .840 \\
5 & .862 & .853 \\
6 & .843 & .890 \\
\hline
\end{tabular}

Note $-N=6, \rho=.826, p<.01$
Table 2b

Spearman Rank Order Correlation Coefficients Between Limited Access Dominance Hierarchies Determined in the Equal 24-H Deprivation Condition, and Condition 1 and Condition 2 in Experiment 2

\begin{tabular}{|c|c|c|}
\hline & Condition 1 & Condition 2 \\
\hline Group & $\begin{array}{l}\text { Submissive } S \text { in } \\
\text { pair deprived } 24 \mathrm{~h} \text {. } \\
\text { Dominant } S \text { in } \\
\text { pair deprived } 48 \mathrm{~h} .\end{array}$ & $\begin{array}{c}\text { Submissive } S \text { in } \\
\text { pair deprived } 24 \mathrm{~h} \\
\text { Dominant } S \text { in } \\
\text { pair deprived } 72 \mathrm{~h}\end{array}$ \\
\hline 1 & .843 & .861 \\
\hline 2 & .867 & .893 \\
\hline 3 & .764 & .850 \\
\hline 4 & .871 & .862 \\
\hline 5 & .903 & .912 \\
\hline 6 & .841 & .880 \\
\hline
\end{tabular}

Note- $N=6, \rho=.826, p<.01$ suggest that an $\mathbf{S}$ who is ranked highly in terms of the number of wins in the social encounter situation tends to be ranked highly in the limited access situation also, and that this relationship does not appear to change significantly as a function of the level of deprivation under which the Ss are competing. These data seem to give added support for similar results found when Ss were tested in separate limited food access and home cage conditions (Candland, Matthews, \& Taylor, 1968).

It is important to note that the absolute number of responses in both the limited access and social encounter conditions increased in all groups as the length of deprivation increased. These increases would be expected as the motivation levels of all $S s$ increased. Relative $S$ changes within the dominance hierarchy do not occur, however, with increases in deprivation levels.

\section{EXPERIMENT 2}

The extreme stability of dominance hierarchies evidenced in Experiment 1 might have been partially augmented by the similar levels of deprivation under which both Ss in a competing pair were operating. The purpose of Experiment 2 was (1) to determine if dominance-submission stability remained when large differentials in the levels of deprivation existed between the dominant and submissive $S s$ in a competitive situation and (2) to determine if relative fatigue had a significant effect in the determination of dominant-submissive relationships. Subjects

Seventy-two male hooded rats of comparable age and weight were used in this study. The experimental group consisted of the 36 original Ss that were tested in Experiment 1 and the remaining $36 \mathrm{Ss}$, which served as the control group.

\section{Apparatus}

The apparatus employed was identical to that used in Experiment 1.
Procedure

Experimental group. Data from the limited access competition in Experiment 1, in which Ss were competing under 24-h deprivation conditions, was analyzed to determine the "winners" and "losers" of individual pairings. This means that a $S$ might be dominant over certain members of the group and submissive to certain other $\mathrm{Ss}$ in the same group.

On the first day of testing, three of the six subgroups were placed randomly into one of two conditions. In Condition 1 the submissive $S$ in a given pairing (Experiment 1 data) was deprived of food $48 \mathrm{~h}$ before competitive testing began, while the $S$ found dominant in the pairing was deprived $24 \mathrm{~h}$. In Condition 2 the submissive member of each pair was deprived $72 \mathrm{~h}$, while the dominant member remained at $24-\mathrm{h}$ deprivation. Random selection of the 15 possible pairings within each subgroup was employed, with no $S$ receiving more than one competition daily. Competitive sessions were procedurally identical to those of Experiment 1. Five-day intervals occurred between competitive testing days. This allowed for a minimum period of at least $48 \mathrm{~h}$ of ad lib feeding (the 72-h deprivation condition) to ensue between deprivation periods. Once each $S$ had been tested with each other member of its group, all groups were placed in the other test condition and testing again resumed.

Control group. The $36 \mathrm{Ss}$ in this group were divided randomly into six subgroups on Day 1 of testing.

All Ss were then placed on 24-h deprivation schedules, and round-robin paired competitive testing identical to that of Experiment 1 was initiated. "Winners" and "losers" of individual pairings were determined within each subgroup.

Three of the six subgroups were then placed randomly into one of two conditions previously discussed for the experimental group. Test procedures were identical to those in Conditions 1 and 2 in the experimental group, except that in the control group the Ss judged dominant in a given pairing were given the longer (48- and 72-h) deprivation periods.

\section{Results and Discussion}

Ss in each subgroup of the experimental group were ranked from most dominant to most submissive in terms of the total number of "wins" in limited access competition during testing in each condition. These rankings were correlated with rankings obtained in Experiment 1, when both members of a given competitive pair were on like 24-h deprivation schedules.

The extreme stability of dominance-submission relationships among $S s$ in a group is shown in Table 2a.

This stability seems to be affected very little by increases in deprivation differentials between dominant and submissive Ss in a competitive pair. In two of the groups, the correlations between the two rankings actually increase as deprivation differentials increase.

The apparent negligible effect of increased motivation per se in producing changes in relative dominance-submission may be explained by noting that both prior learning and/or relative fatigue may tend to counteract expected changes in a submissive $S$ 's behavior. Baenninger (1970) found no significant effect of prior dominance testing in the determination of a S's subsequent competitive behavior, thus eliminating prior learning as a factor of major concern in the interpretation of these results.

The other factor that may significantly affect the results in the experimental group is that of relative fatigue in the submissive $S$ of each competing pair. If fatigue is important as an inhibitor of successful 
competitive behavior, then "dominant" Ss in the control group, which are relatively deprived to a much higher degree than their submissive counterparts, should show decreased success in competition from Condition 1 to Condition 2 testing.

Table $2 b$ shows the relationship between the dominance hierarchies determined when all Ss were deprived equally and those hierarchies obtained when the dominant $S$ received 48 and $72 \mathrm{~h}$ of deprivation. The extreme stability in dominance-submission evidenced in Table $2 b$ tends to dispute the hypothesis that fatigue played any significant role in the original stability of the relationships found in the experimental group.

\section{GENERAL SUMMARY}

On the basis of these data, dominant-submissive behavior appears to be generalizable to different competitive situations. This evidence would disagree with Lindzey, Manosevitz, \& Winston (1966), who found little generalization over different competitive situations.

Deprivation appears to have little affect on the stability of dominance-submission hierarchies, at least in the 24 - to 72 -h range.

This stability is evident not only when both Ss are members of a competing pair under the same level of deprivation, which would agree with data acquired by Schumsky \& Jones (1966), but also is evident when members of the competing pair are under different levels of deprivation, which would seem to disagree with results found in rats with unequal motivation levels (Hsaio \& Schreiber, 1968). The difference between results obtained in this study and those of Hsaio \& Schreiber (1968) may be a function of differences in procedure. Motivational differentials in the Hsaio and Schreiber study were produced largely through different amounts of prefeeding before testing. This procedure cannot, therefore, be considered completely comparable to our procedures.

The high degree of relationship between dominance hierarchies obtained in limited access and social encounter situations was not found by Baenninger (1970) with rats. Again, however, differences in procedure may in part be responsible for differences in results. Baenninger (1970) tested groups of four Ss together in each competitive task. This procedure may produce a much different relationship among group members from those relationships found in a round-robin paired-comparison method.

\section{REFERENCES}

BAENNINGER, L. P. The reliability of dominance orders in rats. Animal Behaviour, 1966, 14, 367-371.
BAENNINGER, L. P. Social dominance orders in the rat: "Spontaneous," food, and water competition. Journal of Comparative \& Physiological Psychology $1970,71,202-209$.

CANDLAND, D. K., \& BLOOMQUIST, D. $W$. Interspecies comparisons of the reliability of dominance orders. Journal of Comparative \& Physiological Psy chology, 1965, 59, 135-137.

CANDLAND, D. K., MATTHEWS, T. J., \& TAYLOR, D. B. Factors affecting reliability of dominance orders in the domestic chicken. Journal of Comparative \& Physiological Psychology, $1968,66,168-174$

CORMAN, C. D., \& RUSKIN, R. S. Free operant competition under two schedules of reinforcement. Paper presented at annual meeting of Psychonomic Society, 1969.

GRANT, E. C., \& CHANCE, M. R. Rank order in caged rats. Animal Behaviour. $1958,6,183-194$

HSAIO, S., \& SCHREIBER, S. C. Social dominance and motivational variables in rats. Psychonomic Science, 1968, 10 , 117-118.

KENDALL, M. G. Rank correlation methods. (2nd ed.) New York: Hafner, 1955.

LINDZEY, G MANOSEVITZ, M., \& WINSTON, H. D. Social dominance in the mouse. Psychonomic Science, 1966, 5 , 451-452.

SCHUMSKY, D. A., \& JONES, P. D Reliable paired comparison dominance orders in rats. Psychological Record, $1966,16,473-478$

UYENO, E. T. Hereditary and environmental aspects of dominant behavior in the albino rat. Journal of Comparative \& Physiological Psychology. $1960,53,138-141$.

\title{
Strain differences in rotating wheel activity of the rat*
}

\author{
GORDON M. HARRINGTON† \\ University of Northern Iowa, Cedar Falls, Iowa 50613
}

Parametric comparisons of activity in a wheel were made for 694 rats from 12 inbred strains: ACI, A990, A35322, F344, INR, IR, MNR, MNR-â, MR, TS1, WAG. Where comparable, the data were consistent with the data of previous studies, though pointing toward different interpretations.

The rotating cage or activity wheel has long been one of the common measurement devices for motor activity. Rundquist $(1931,1933)$, in a selection study continued by Brody $(1942,1950)$, seems to have been the first to demonstrate the heritability of motor activity in rats, as measured in activity wheels. Fuller \& Thompson (1960) have presented a rather detailed critical review of these and some of the other major works on the genetics of activity. However, the investigator who needs parametric data to select an appropriate strain for his research or to assess the comparability his have with others will be hard pressed if he uses rats rather than some other species which is genetically well documented. This study provides comparative data for wheel activity of 12 inbred strains of rats.

\section{METHOD}

The Ss were 694 rats from 12 inbred strains, bred and maintained in

*This research was supported by Faculty Research Grant 302-40 of the University of Northern lowa.

II am indebted for the assistance of $\mathrm{my}$ colleague, Dr. L. R. Hellwig, and my principal assistants. James $R$. Hanlon, Tom $M$. Hughes, Nissan Buium and Joyce $M$. Schima. the writer's laboratory as follows: ACI, black, agouti, Irish, 44 males and 29 females; A990, black, agouti, hooded, 25 males and 22 females; A35322, black nonagouti, hooded, 31 males and 27 females; F344, albino, nonagouti, hooded, 35 males and 31 females, INR, black, nonagouti, hooded, 21 males and 15 females; IR, dilute, nonagouti, hooded, 33 males and 31 females; MNR, albino, agouti, hooded, 10 males and 10 females; MNR-a. albino, nonagouti, hooded, 31 males and 29 females; MR, albino, nonagouti, hooded, 24 males and 22 females; TS1, black, agouti, Irish, 43 males and 47 females; TS3, black, nonagouti, 37 males and 36 females; WAG, albino agouti, hooded, 32 males and 23 females. The preceding lines are sometimes referred to in the literature by the following synonyms, respectively: AxC9935, August 990, August 35322, Fischer 344, Iowa Nonreactive or Hall Nonreactive, Iowa Reactive or Walker, Maudsley Nonreactive, Maudsley Nonreactive a subline, Maudsley Reactive, Tryon Maze Bright, Tryon Maze Dull, Wistar Albino. The INR, IR, TS1, and TS3 lines were derived from selective breeding and maintained for many 